Gut, 1963, 4, 279

\title{
Adult coeliac disease
}

\author{
W. T. COOKE, D. J. FONE, E. V. COX, M. J. MEYNELL, \\ AND R. GADDIE
}

From the General Hospital, Birmingham

EDITORIAL SYNOPSIS A clinical, biochemical, and pathological study is recorded of 50 patients in whom a diagnosis of idiopathic steatorrhea had been made and who had 'flat' jejunal biopsies. It is suggested that there is an underlying constitutional defect, not yet clearly defined, and that possibly secondary intestinal infection allows the intestinal mucosa to become sensitized to substances in the diet. Of these gluten is the commonest; milk adversely affects others; and there may be other factors.

Idiopathic steatorrhoea is composed of many entities, and of these, one with characteristic changes in the jejunal mucosa has been termed adult coeliac disease (Cooke, 1958). Fone, Cooke, Meynell, Brewer, Harris, and Cox (1960), following a survey of 58 patients with idiopathic steatorrhoea, concluded that there were both clinical and histological differences to be found which allowed differentiation of at least two groups, one characterized by mild anaemia, recurrent diarrhoea, and 'flat' jejunal biopsies, adult coeliac disease, and a second in which there was a high incidence of severe megaloblastic anaemia, steatorrhoea, and absence of 'flat' biopsies for which there was no satisfactory term. Girdwood, Delamore, and Wynn Williams (1961), however, concluded that there was no histological or haematological evidence to justify such a differentiation. Frazer (1960), on the other hand, suggests that there is a type of idiopathic steatorrhoea which should be called gluten-induced enteropathy, responding specifically to the withdrawal of gluten from the diet. Therefore, in this paper the life history, laboratory findings, and the effects of therapy are presented concerning a group of patients with idiopathic steatorrhoea and a 'flat' jejunal biopsy (adult coeliac disease) in order to provide more factual evidence. The data are also made available as a basis for comparison with other closely related conditions which are usually included under the diagnosis of idiopathic steatorrhoea.

\section{CASE MATERIAL}

Patients for jejunal biopsy were selected randomly from a series of 200 patients with a diagnosis of idiopathic steatorrhoea. The first 50 with a flat biopsy are considered. There were 27 women and 23 men. The period of observation varied from one year to 20 years with a mean of $\mathbf{9 . 2}$ years. Apart from attendances for special investigations, all have been seen regularly at intervals of three, six, or 12 months.

AGE OF PRESENTATION The age at which these patients were first seen at the General Hospital ranged from $1 \frac{1}{2}$ to 63 years; 31 or $62 \%$ presented between 35 and 55 years of age (Fig. 1). This was also a close approximation to the age at which the diagnosis had been made in adult life. Nevertheless, 26 had been diagnosed as suffering from coeliac disease in childhood or had had symptoms of sufficient severity to justify that assumption.

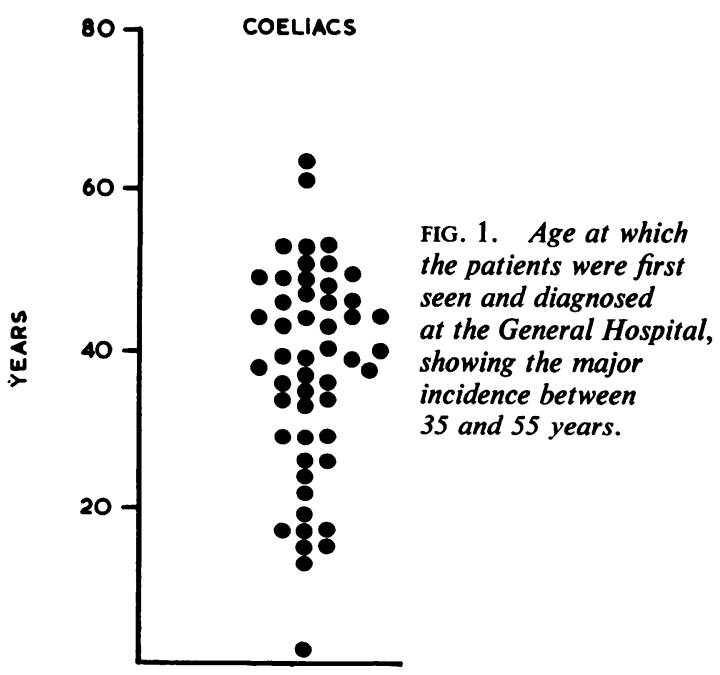




\section{METHODS}

Jejunal biopsies were carried out with the Crosby capsule. Serum levels of vitamin B12 were determined with Lactobacillus leishmanii (Meynell, Cooke, Cox, and Gaddie, 1957). The folic acid activity in the serum and whole blood were determined with Lactobacillus casei (Waters and Mollin, 1961) and in whole blood also with Streptococcus faecalis (Meynell, 1962). Absorption of $58 \mathrm{CoB} 12$ was estimated by the hepatic uptake method (Fone, Cooke, Meynell, and Harris, 1961). Other investigations included ionized calcium (Fowler, Fone, and Cooke, 1961), folic acid excretion test (Cox, Meynell, Cooke, and Gaddie, 1958), d-xylose excretion test (Fowler and Cooke, 1960), urinary Figlu by a paper chromatographic method (Fowler, 1961) and the quantitative method of Tabor and Wyngarten (1958), serum proteins by a modification of the method of Weichselbaum (1946), urinary amino-acids (Fowler, Cox, Cooke, and Meynell, 1960), seromucoids (Cooke, Fowler, Cox, Gaddie, and Meynell, 1958), and alkaline phosphatase (King, Haslewood, Delory, and Beall, 1942).

\section{CLINICAL FEATURES}

The symptoms and clinical features of idiopathic steatorrhoea have been described previously by one of us (Cooke, Peeney, and Hawkins, 1953) and in general are those encountered in this group with flat jejunal biopsies, namely, mild chronic ill health, recurrent glossitis, mild anaemia, and variable degrees of intestinal upset. However, three features deserve more emphasis, the incidence of diarrhoea, the frequency of metabolic bone disease, and the occurrence of neuropathy. Diarrhoea was the principal symptom in at least 40 patients with adult coeliac disease. It was never absent. Nevertheless, symptoms of lassitude and loss of weight due to the constitutional upset of the disorder are difficult to separate from those caused by diarrhoea, for it is these symptoms which make the patient seek advice about the bowel upset. More recent experience has lead us to believe that intercurrent infection is a common cause of relapse. Although non-specific influenza-like infections in normal subjects may produce looseness of bowels for one or two days, in patients with adult coeliac disease they frequently result in severe bowel disorders lasting many weeks.

Nine patients developed the classical waddling and sore-footed gait of osteomalacia during the period of observation. These had bone tenderness together with many others who had biochemical evidence of this condition and radiological rarefaction of bones.

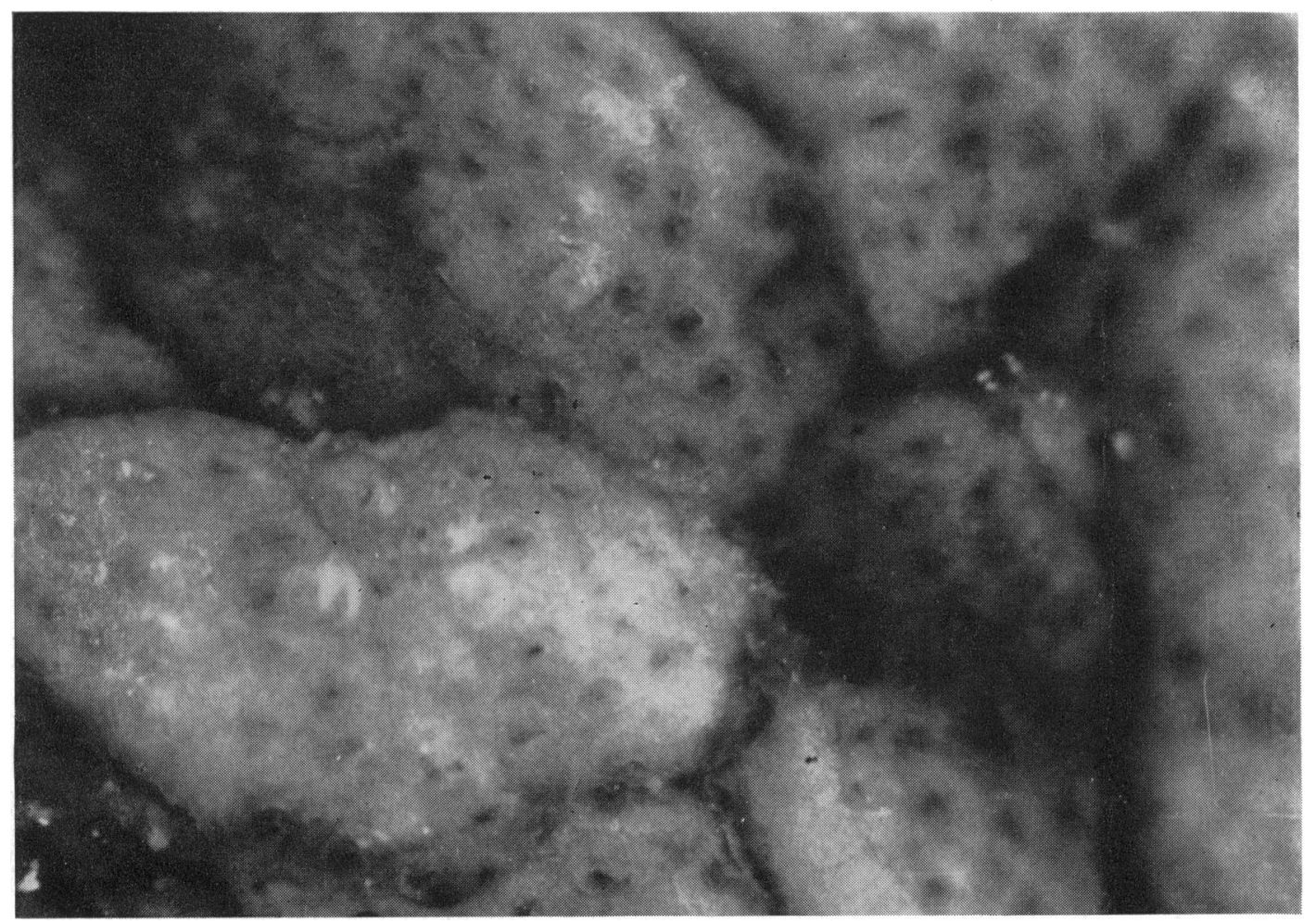

FIG. 2. Appearance of flat biopsy under dissecting microscope showing the lobulated pattern. 
Neuropathy has been described under the term 'progressive neuromyeloradiculitis' or 'pseudotabes' by Sencer (1957). Superficially the features suggest subacute combined degeneration of the cord commencing with a picture of peripheral neuritic and posterior column disturbance affecting the lower limbs. This type of neuropathy developed in four of the 50 patients in this group, the lesions developing while under our care in three. Case 2 became ataxic and lost the leg reflexes, but before becoming incapacitated died from coronary thromtosis. Case 37 had a rapidly progressive neuropathy from which he died 18 months after the onset. Case 34 developed severe muscle weakness, absent leg reflexes, and gross ataxia from which she has made a gradual recovery. She was severely disabled for two years. Case 41 is still grossly disabled with a cerebellar type of incoordination of the arms and legs, three years after its onset.

\section{LABORATORY FINDINGS}

JEJUNAL BIOPSIES Under the dissecting microscope 'flat' biopsies were readily recognized by the absence

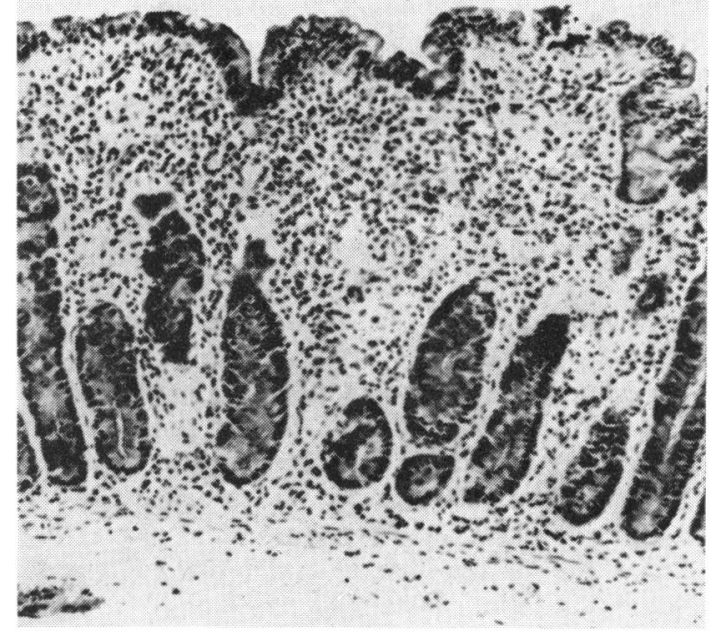

FIG. 3. Typical histological appearance of 'flat' biopsy showing the absence of normal villi; abnormal surface epithelial cells.

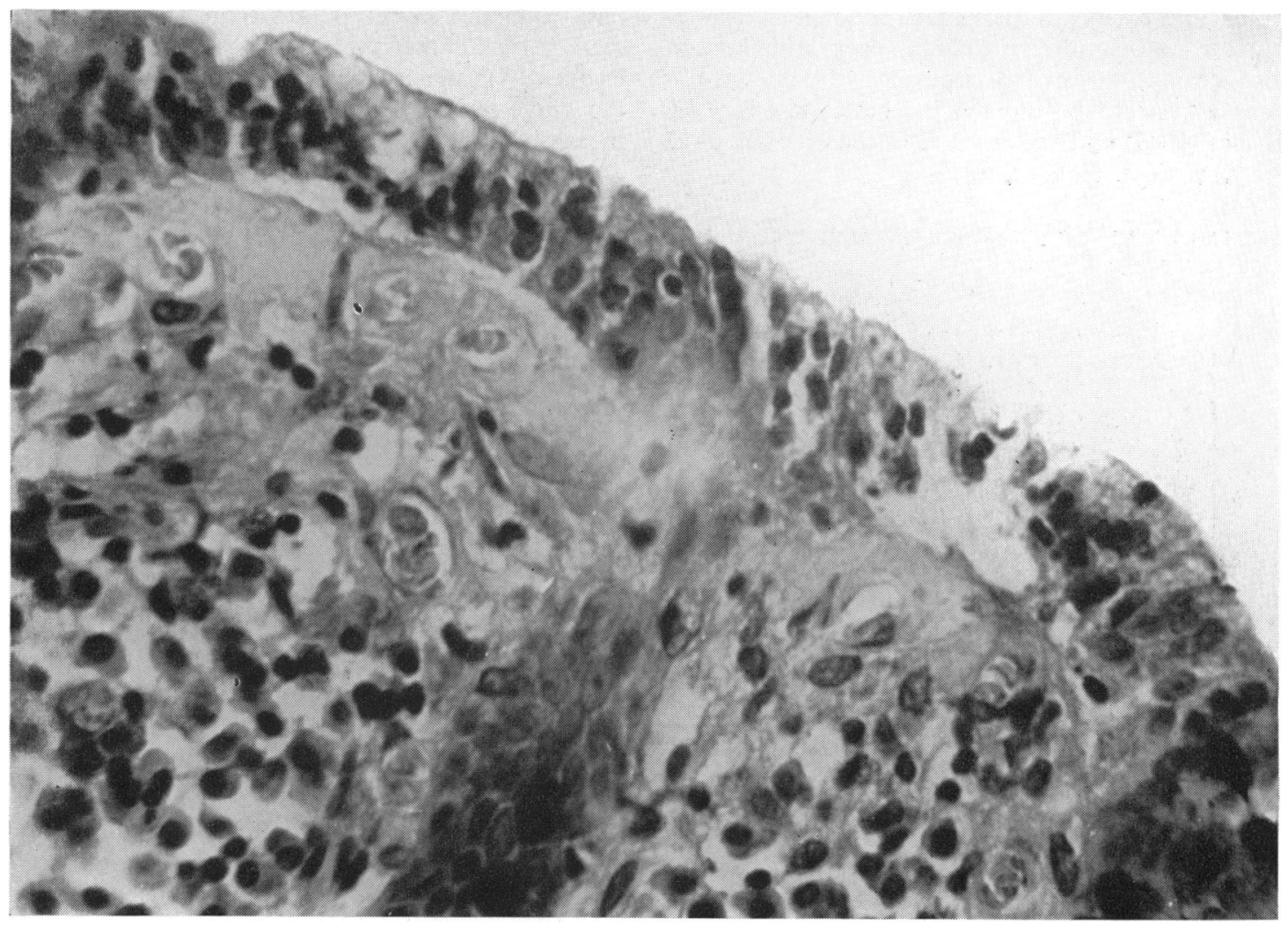

FIG. 4. Area of homogeneous substance beneath the surface epithelium, staining poorly with Schiff's periodic-acid technique, reticulin, and Van Gieson. 
of villi and the appearance of a lobulated mucosal surface, the area enclosed by the lobule having relatively few crypt openings (Fig. 2).

Histological details by light microscopy of the flat biopsy used as the criterion for inclusion in this study has been given by Fone et al. (1960), in great detail by Padykula, Strauss, Ladman, and Gardner (1961), and as 'total villous atrophy' by Shiner and Doniach (1959). A typical section is illustrated in Figure 3. The mucosa is of normal or reduced width and the surface flattened with no normal villi present. Villi when present were broad and short and tended to fuse together, again giving a flattened appearance. The surface epithelium was always abnormal, the cells being cuboidal or flattened and the brush border reduced in width or sometimes not visible. The nuclei of the surface epithelium were varied in shape, size, and degree of staining, and often crowded together. The glandular tubules were normal or reduced in number and often elongated and dilated. Crypts of Lieberkuhn were infrequent and widely spaced. There were variable degrees of cellular infiltration of the lamina propria. In many biopsies, there were areas of homeogenous eosinophilic material immediately beneath the surface epithelium separating it from the underlying lamina propria. In contradistinction to the earlier statement by Fone et al. this does appear to be the hyaline band described by Schein (1947) and was present in the biopsies of 21 (42\%) patients (Fig. 4).

HAEMATOLOGY Thirty patients had red cell counts of
4 million/c. mm. or more and haemoglobin concentrations greater than $11.5 \mathrm{~g} . \%$ (Fig. 5). Six patients had haemoglobin values of less than $7.9 \mathrm{~g}$. \%. Of these, three had moderately severe megaloblastic anaemias (cases 2, 15, and 38). Cases 2 and 38 had a severe diarrhoea due to a superimposed intestinal infection. Case 15 had a severe leucopenia and noma oris (see Fig. 2, Witts 1952). Of the remaining three with low haemoglobin values, case 50 had a red cell count of 1.96 million/c. $\mathrm{mm}$. with a haemoglobin concentration of $6.8 \mathrm{~g} . / 100 \mathrm{ml}$. when first seen but with delay of admission had remitted to $8.6 \mathrm{~g}$. $/ 100 \mathrm{ml}$. when seen two months later without having received any haematinic therapy as far as can be verified. Case 19 had a severe hypochromic anaemia (haemoglobin $6.8 \mathrm{~g}$. $/ 100 \mathrm{ml}$.) due to menorrhagia. Following removal of fibroids and oral iron therapy, she regained normal blood levels which she has maintained for the last 12 years without further therapy. Case 11, who had a pleural effusion thought to be tuberculous and a haemoglobin of $6.6 \mathrm{~g} . / 100$ $\mathrm{ml}$., had a normoblastic bone marrow and remitted satisfactorily with iron therapy (see case 4 of Hawkins, Peeney, and Cooke, 1950). Five patients had white cell counts of less than 3,500 when first seen. Sternal marrow examinations were made frequently in the earlier patients of the series but in the whole series 17 were carried out, in 11 of which megaloblastic erythropoiesis was present.

BLOOD GROUPS Joske and Benson (1958) found that the incidence of group $\mathbf{O}$ was significantly high in

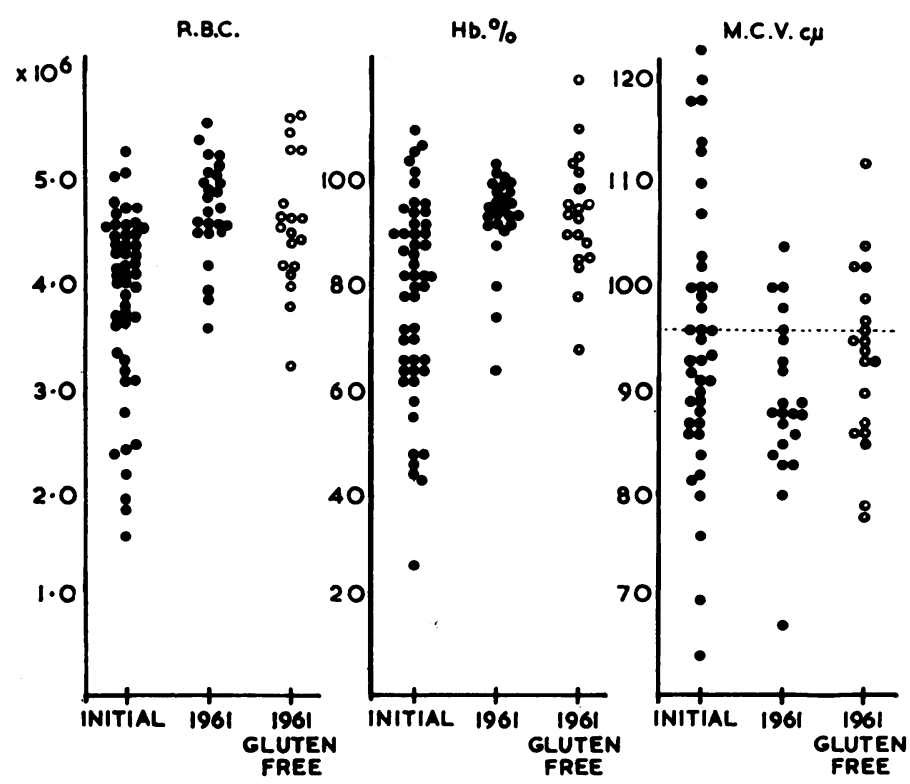

FIG. 5. The initial red cell counts, haemoglobin $(14.8 \mathrm{~g} .=100 \%)$, and mean cell volume of the 50 patients when first seen, and the findings at the end of 1961 of those treated with a gluten-free diet and those not so treated. 
idiopathic steatorrhoea, in 20 out of 28 patients. Blood groups were determined in 46 patients. The proportions were group A $50 \%$, group AB $2.2 \%$, group B $4.3 \%$, group O $43.5 \% ; 87 \%$ were Rhesus positive. These results are not significantly different from those of the general population.

FOLIC ACID METABOLISM Folic acid excretion tests were carried out in 33 patients. The mean excretion following the intramuscular dose of $5 \mathrm{mg}$. was $2.37 \mathrm{mg}$. in 24 hours (s. D. 0.19) and that following the oral dose $0.44 \mathrm{mg}$. (s. D. 0.18) (Fig. 6). Two patients, cases 9 and 21 , had tests falling within the normal range. Case 9 had normal tests on two occasions $(2 \cdot 20 / 1.96$ and $2 \cdot 28 / 2.39)$ but on the third occasion 18 months later it was abnormal (2.82/1-23). Case 21, who had severe coeliac disease as a child, had a normal excretion test (3.07/2.29). At that time, his faecal fat excretion measured over six days was within normal limits.

Blood 'folic acid' levels were determined at intervals on 15 patients during the second part of the folic acid excretion test, i.e., following an oral test dose of $5 \mathrm{mg}$. The results (Fig. 7) are significantly different from those found in normal subjects, showing a relatively small rise in blood folic acid activity.
Estimations of the folic acid activity (as determined by $L$. casei and Strep. faecalis) were made on serum and whole blood of a random number of the patients under consideration. While the determinations with $L$. casei on serum and whole blood were in general lower than those on control subjects, the most striking finding was the low folic acid activity of whole blood as determined with Strep. faecalis (Fig. 8).

Urinary formiminoglutamic acid following a loading dose of histidine was determined in only five of these patients before therapy and was present in moderate amounts in four and in trace amounts in one.

IRON METABOLISM Of the 39 patients in whom serum iron was determined initially, 11 had values less than $40 \mu \mathrm{g}$. per $100 \mathrm{ml}$.: eight subsequently developed similar low values. Of the remaining 11 patients, seven had low values when the determination was eventually performed. Thus 26 or $52 \%$ had severe hypoferraemia at some time during the period of observation.

B12 METABOLISM AND GASTRIC FUNCTION Forty-four patients had free gastric acid, albeit often in small

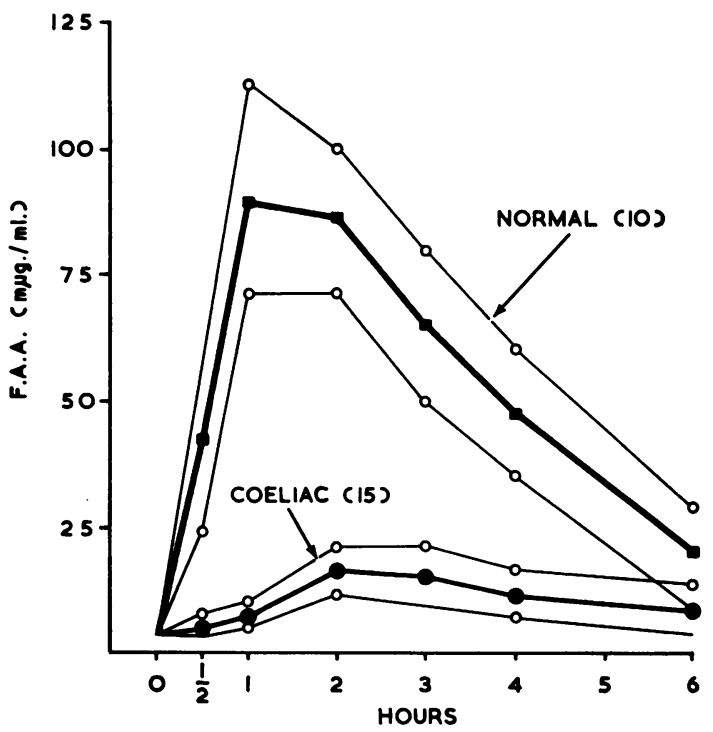

FIG. 7. Comparison of folic acid levels following oral ingestion of $5 \mathrm{mg}$. folic acid in 10 normal subjects and 15 patients with adult coeliac disease. The five lines represent twice the standard error of the mean.

FIG. 6. Folic acid excretion indices $=\frac{\text { (Urinary excretion after } 5 \mathrm{mg} \text {. folic acid orally) }}{\text { (Urinary excretion after } 5 \mathrm{mg} \text {. folic acid intramuscularly) }} \times 100$ in 33 patients with adult coeliac disease. 


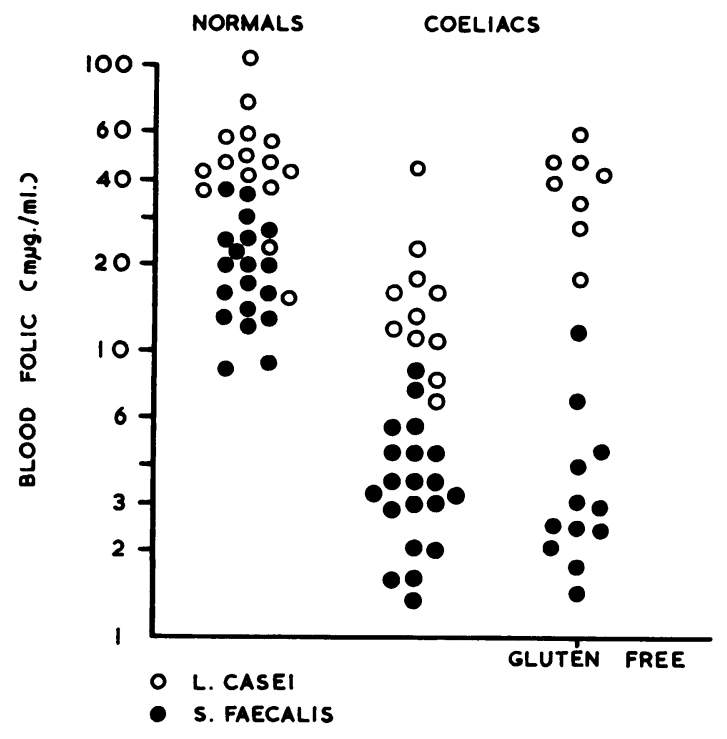

FIG. 8. The whole blood values for folic acid activity determined by Lactobacillus casei and by Streptococcus faecalis in normal subjects and in patients treated with a gluten-free diet or not.

amounts. Of these, 35 absorbed $58 \mathrm{CoB}_{12}$ normally and four had impaired absorption of $58 \mathrm{CoB}_{12}$, even with the simultaneous administration of intrinsic factor. Of the five in whom the absorptive capacity for $58 \mathrm{CoB}_{12}$ was not checked, four had consistently normal levels of serum vitamin B12; the fifth had had low serum levels and received parenteral therapy.

Five had no free gastric acid following maximum stimulation with histamine. Of these five, four absorbed radioactive B12 normally. These four patients had been known to have had a histaminefast achlorhydria for six, eight, 17, and 17 years respectively before investigation of the hepatic uptake, and the gastric findings have been confirmed during the last six months using the maximum histamine test meal. Gastric biopsies in three of these patients showed marked gastric atrophy. The fifth patient (case 13) had an impaired uptake of $58 \mathrm{CoB}_{12}$ alone (756) and also with the addition of intrinsic factor (536); gastric juice from this patient administered with $58 \mathrm{CoB}_{12}$ to a patient with pernicious anaemia demonstrated the presence of intrinsic factor. His gastric biopsy showed atrophic gastritis. The remaining patient (case 3 ) had neither his gastric contents nor hepatic uptake checked, but the serum levels of vitamin B12 were normal. His gastric biopsy showed severe atrophy. To summarize, of the group of 50 patients, absorption of $58 \mathrm{CoB}_{12}$ was normal in $\mathbf{4 4}$ and impaired in six and there is strong evidence that intrinsic factor was present in all.
Estimation of the level of serum vitamin B12 was not carried out before 1956 but in general the level of serum $\mathrm{B} 12$ reflected the ability of the patient to absorb $58 \mathrm{CoB}_{12}$. Exceptions were noted in three patients in whom there was evidence of deficiency of either folic acid or iron or both. Though the B12 levels returned to normal with the appropriate therapy, they remained in the lower range of normal (Cox, Cooke, Meynell, and Gaddie, 1962; Mollin, Waters, and Harriss, 1962). Similar low levels were found in a few patients who had normal levels when first seen but with the institution of therapy with folic acid, iron, or a gluten-free diet, the levels fell eventually, returning to normal without the administration of B12.
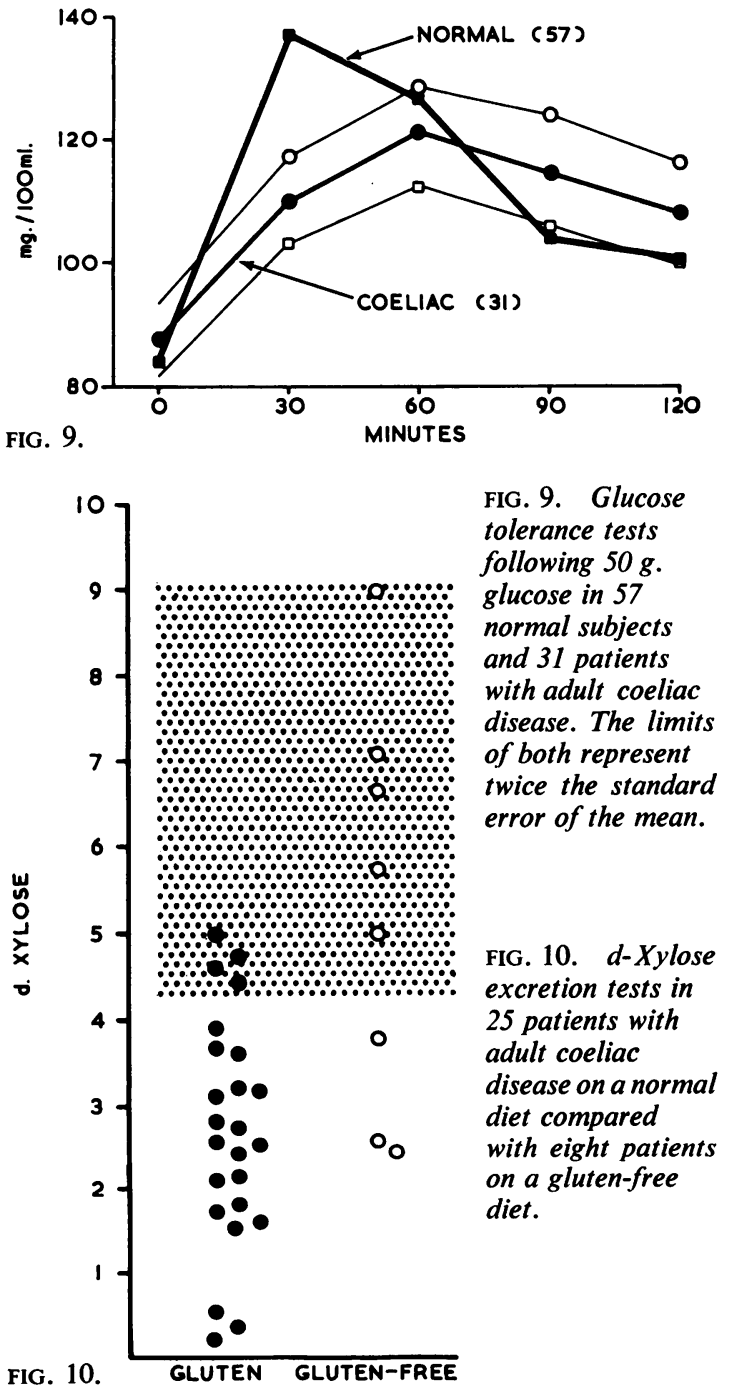
CARBOHYDRATE METABOLISM Glucose tolerance tests were carried out in 31 patients and are depicted in Figure 9. There was a delayed rise in the first $\mathbf{3 0}$ minutes but thereafter the levels fell within the normal range. Urinary excretion of d-xylose five hours following $25 \mathrm{~g}$. d-xylose orally was determined in 25 patients. The excretion of four fell within the lower limits of our normal range $(4.5,4.5,4.6$, and $5.0 \mathrm{~g}$.), the lower limit of normal being 4.2 with a mean of $6.7 \mathrm{~g}$. (Fig. 10).

PROTEIN METABOLISM Serum proteins were determined at the time of presentation in 47 patients (Fig. 11). The serum albumin was less than $4 \cdot 1 \mathrm{~g}$. in 27 patients (normal range 4.1 to $5.2 \mathrm{~g}$. per $100 \mathrm{ml}$.). Only three patients had serum globulins less than $1 \cdot 8$, the lower limit of normal. The serum of 21 patients was examined by paper strip electrophoresis (Table I). This confirmed the tendency to low serum albumin found on chemical analysis. A significant increase in $\alpha_{1}$ and $\gamma$ globulins was also noted. There were no patients with hypogammaglobulinaemia.

Faecal nitrogen was increased in these patients when it was estimated, agreeing with previously published work showing a correlation between the faecal nitrogen and faecal fat (Cooke, Thomas, Mangall, and Cross, 1953). The faecal excretion of intravenously injected P.V.P. ${ }^{131}$ I excretion was determined in seven patients. In six the values were increased, the percentage of the ingested dose varying from 1.3 to $6.8 \%$. In each instance, faecal nitrogen was increased.

Urinary excretion of amino-acids was normal in eight patients. Seven had a moderate increase in amino-acidscomparable to that seen in megaloblastic anaemias (Fowler et al., 1960). In case 33, aminoaciduria was gross and gradually disappeared with improvement in the patient's general condition over 18 months. The 5-hydroxyindole acetic acid excretion was normal in 12 patients, i.e., less than $5 \mathrm{mg}$. per 24 hours. It varied between 5 and $10 \mathrm{mg}$. in one and between 15 and $20 \mathrm{mg}$. in another.

Multiple seromucoid estimations were made on the sera of 33 patients. In general the values were normal when the patient was well. They were, how-

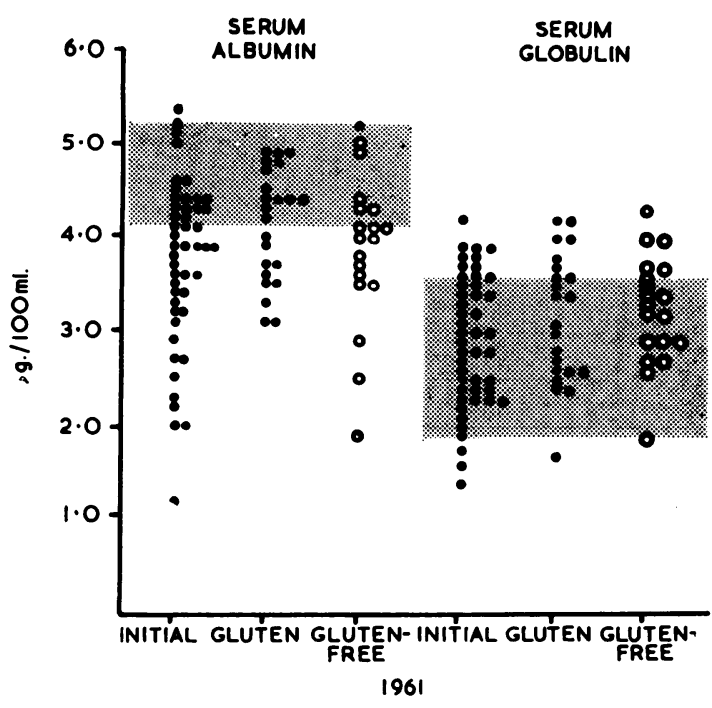

FIG. 11. The serum levels of albumin and globulin in 47 patients with adult coeliac disease when first seen compared with the findings in 1961 in those on a normal diet and those on a gluten-free diet. The shaded areas represent the range of normal values.

ever, raised in 14 patients, in some of whom there was evidence of superimposed infection but in others no obvious explanation was found.

SENSITIVITY TESTS The sera of 31 patients were tested for the presence of antibodies to milk proteins and gluten by the tanned red cell technique. Raised titres to casein were found in 15 out of 30 with titres ranging from $1 / 50$ to $1 / 10,000$ to fraction III (Frazer, Fletcher, Ross, Shaw, Sammons, and Schneider, 1959), in six out of 30 with titres up to $1 / 200$ to $\alpha$ lactalbumin, in 23 out of 30 with titres up to $1 / 100,000$, and to $\beta$ lactoglobulin in 23 out of 31 with titres up to $1 / 100,000$. The incidence of these high titres was greater than in control groups with regional enteritis, ulcerative colitis, and postgastrectomy states. More detailed evidence will be presented elsewhere.

TABLE I

COMPARISON OF PROTEIN FRACTIONS BY PAPER ELECTROPHORESIS OF 17 NORMAL SUBJECTS AND 21 PATIENTS WITH ADULT COELIAC DISEASE NOT ON A GLUTEN-FREE DIET

Normal subjects

Patients with adult coeliac disease

Student's test

\begin{tabular}{clccccc} 
No. & & Albumin & $a 1$ & $\alpha 2$ & $\beta$ & \\
\hline 17 & Mean & 4.31 & 0.32 & 0.61 & 0.84 & 1.37 \\
21 & S.E. & 0.05 & 0.02 & 0.02 & 0.02 & 0.09 \\
& Mean & 3.53 & 0.40 & 0.64 & 0.81 & 1.68 \\
& S.E. & 0.02 & 0.06 & 0.04 & 0.04 & 0.08 \\
& P & 0.001 & 0.01 & - & - & 0.001
\end{tabular}



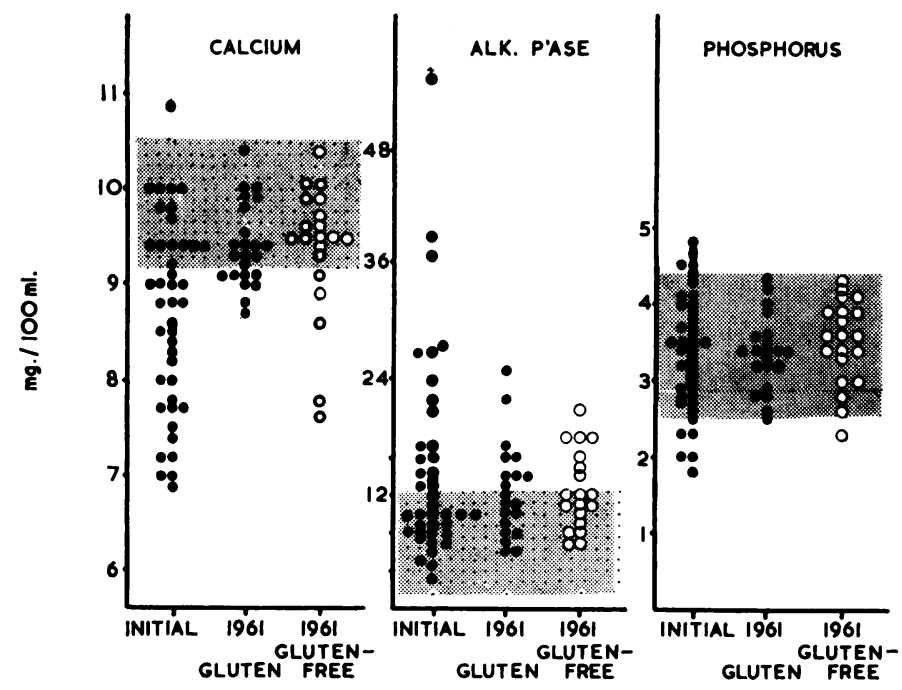

FIG. 12. Serum levels of calcium, phosphorus, and phosphatase in patients with adult coeliac disease when first seen compared with the findings in 1961 in those on a normal diet and those on a gluten-free diet. The shaded areas represent the range of normal values.
CALCIUM AND PHOSPHORUS METABOLISM Of the 44 patients who had an initial estimation of the serum calcium, 28 had values less than $9 \cdot 2 \mathrm{mg}$. $/ 100 \mathrm{ml}$. In 15 patients, the calcium fractions were determined and have been published elsewhere (Fowler et al., 1961). The lowest levels of total diffusible and ionized calcium were found in three patients with osteomalacia (Fig. 12).

Serum phosphorus determinations showed little deviation from normal though the levels were raised in some patients. Of 40 patients who had the alkaline phosphatase estimated initially, 20 had values greater than 12 King-Armstrong units. Of those not initially determined or who had normal values when first seen, 13 showed raised values subsequently. Thus of the 49 patients on whom the serum alkaline phosphatase was determined, raised values were encountered in 33. Bone biopsy of the iliac crest was carried out in seven patients; necropsy material was available in one of these and in one other patient. Five showed both osteomalacia and osteoporosis (cases 1 , $2,3,6$, and 36). Three showed no significant change despite evidence of chemical osteomalacia-lowered serum calcium and raised alkaline phosphatase levels.

RADIOLOGY Radiological survey of the skeleton was carried out in 37 patients. Demineralization was evident in 27 patients, and as might be expected, was more common in older patients. Radiological abnormality of the small intestine was present in all the patients though it was minimal in two patients. The findings were similar to those described by many workers.

\section{COURSE OF THE DISORDER}

Five patients have died. Case 3, a man aged 35, was killed in a motor cycle accident three years after first being seen. At that time he had been unable to work for two years. Treatment with steroids had resulted in considerable improvement so that he had completed a rehabilitation course and was about to restart work. Case 2 had been followed for 18 years, working regularly until normal retirement when he developed signs of neuropathy and osteomalacia. He had been treated regularly with vitamin B12 and folic acid but died of a coronary thrombosis aged 67 years. Case 20 , a man aged 67 at death from carcinoma of the oesophagus, had worked regularly for 18 years, receiving a crude liver extract injection every two weeks, maintaining normal blood counts and excellent health from the time he was first treated. Three other patients with idiopathic steatorrhoea not included in this series died subsequently from carcinoma of the oesophagus. Case 6 was first seen with diarrhoea due to adult coeliac disease. One month later he was admitted with a high swinging temperature and radiological evidence of lung consolidation. He died four months later. Necropsy revealed a chronic granulomatous infection of the lung with no evidence of neoplasm. His case is being reported in detail elsewhere. Case 27, a man aged 35, was first seen with diarrhoea and a severe progressive neuropathy which did not respond to vitamin B12 and a gluten-free diet.

The age of presentation of this group of patients has been mainly between 35 and 55 even in those whose disorder started in childhood. For example, 
case 5 had had coeliac disease as a child, served in the Navy, graded A1 for five years from the age of 20 to 25 , and then developed diarrhoea at the age of 33 years. A striking example, case 54 , not included in this series, had severe intestinal upsets in childhood, had taken part in much heavy infantry fighting for five years, and at the age of 35 developed diarrhoea again and osteomalacia. His son, now aged 13, has had proven coeliac disease since the age of 2 years. Case 30, now aged 70, had intestinal disturbances and rickets in childhood. Though she had continued to have two or three loose stools daily for the rest of her life and had severe skeletal deformities, she worked regularly and maintained herself without seeking medical attention until the age of 63 when increasing diarrhoea brought her to seek advice. This pattern of illness of varying severity in childhood, followed by good health during the third and fourth decades of life irrespective as to whether they had received treatment and the later reappearance of symptoms, was the common course in many of this group of patients. The illness which brought them to seek advice in adult life was often relatively transitory even though severe at the time.

\section{EFFECT OF THERAPY}

Many patients had been treated with replacement therapy and a low-fat, high-protein diet before the introduction of the gluten-free régime. Subsequently patients with more severe symptoms were treated with this diet though two of these refused to persist with this regimen. Analysis of the whole group showed no marked difference in the severity of the initial symptoms in those who were treated with a gluten-free diet and those who were not.

HAEMATINICS OR NONE Twenty-five patients take diets containing gluten though usually restricting their intake of fried foods, meat fats, and pastry. All are clinically well, working regularly or doing full household duties. Of these, seven, apart from an initial period of therapy, have received no treatment for periods of five to 14 years. Case 19, a woman of 57 , has remained well since being seen at the age of 43 and having received oral iron therapy for only six months. She still has a flat biopsy and increased fat in her stools. Case 16, a girl now aged 19, was first diagnosed at the age of $1 \frac{1}{2}$, has had no therapy for 10 years. She has a flat biopsy, has maintained normal blood counts, has no intestinal symptoms, and is taking a normal part in students' life at a teachers' training college. Case 29 , now aged 66 , has had no therapy for five years. She claims that she is in better health than she has ever been. Case 21 (see Fig. 4, Parsons and Barling, 1954), now aged 32, has had no therapy for 12 years, and in spite of his severe coeliac trouble in childhood he eats approximately $30 \mathrm{~g}$. gluten per day. His most recent faecal fat estimation averaged $4.5 \mathrm{~g}$. per day over six days. His absorption of $58 \mathrm{CoB}_{12}$, folic acid, and xylose excretion tests are normal. His jejunal biopsy is flat.

The average gain in weight of these 25 patients since first being seen was $10 \mathrm{lb}$. and was invariably gained within the first 12 months of treatment. Only one patient (case 46) has lost weight $(5 \mathrm{lb}$.). Though he had been treated with a gluten-free diet for nine months, he was markedly oedematous when first seen. He subsequently made an excellent recovery with steroid therapy and has maintained this for the past five years. One further patient (case 3) has been treated for the last four years with steroids and has remained the same weight. At the time he was seen initially, he had marked leg oedema, osteomalacia with pseudo fractures, and a mild megaloblastic anaemia. He refused to persevere with a gluten-free diet but on triamcinalone, $4 \mathrm{mg}$. daily, and calciferol rapidly regained normal health and the ability to perform heavy manual work.

Four patients receive vitamin B12 parenterally, three because they do not absorb it, and case 11, although absorption of $58 \mathrm{CoB}_{12}$ is normal, because

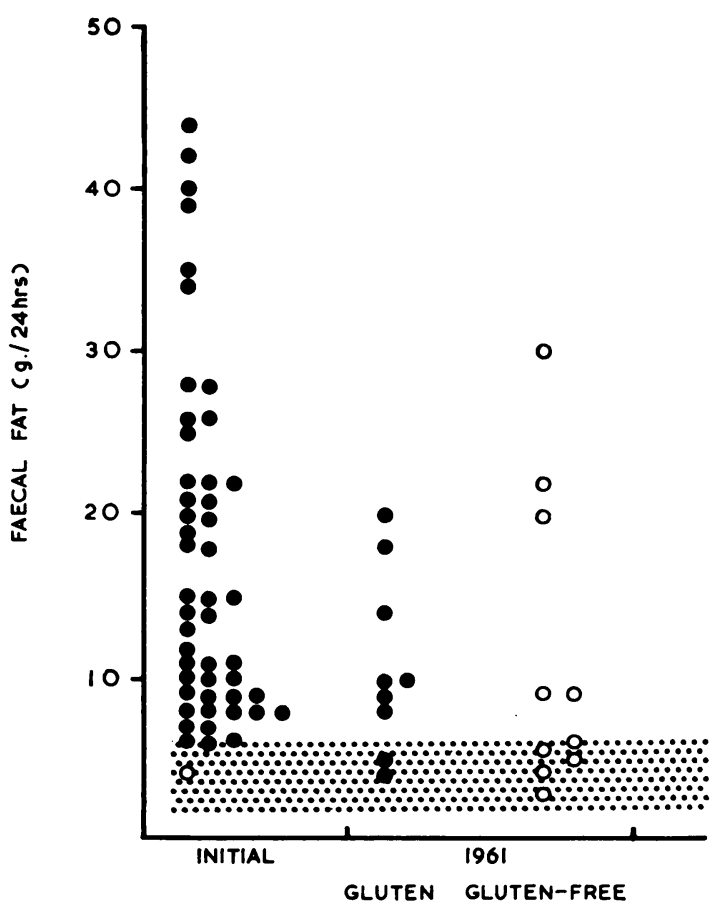

FIG. 13. Daily faecal fat excretion of 50 patients with adult coeliac disease compared with the findings in 1961. 
she has received it for many years and wished to continue.

Ten patients receive folic acid regularly. Another patient (case 16), the only one not maintaining normal blood counts, claims to have abdominal pain when she takes a gluten-free diet. She has had no therapy for 12 months and is iron deficient.

Eight still have serum albumin values of less than 4.1 g. (Fig. 8). Also the serum alkaline phosphatase is greater than 12 units in nine patients. Whilst serum calcium is still low in eight the serum phosphorus levels fall within the normal range. Faecal fat excretion is normal in two of the nine patients checked (Fig. 13). Repeat biopsies on three patients showed no significant change.

GLUTEN-FREE DIET Twenty patients have been treated with a gluten-free diet for an average period of 36 months. Three patients receive folic acid in addition. Several have had courses of oral iron. The average gain in weight was $11 \mathrm{lb}$. Irrespective of the laboratory or biopsy findings, good clinical results have been obtained in all but two (cases 41 and 43) who have been on diet for 60 and 84 months respectively. Faecal fat excretion was normal in five out of the 10 patients checked. Two patients have a mild macrocytic anaemia and seven an increased mean cell volume. The serum iron was low in two patients; there was no evidence of blood loss. Figlu was excreted in excess in the urine of three of the four patients tested following loading with histidine.
Raised levels of alkaline phosphatase were present in seven patients. Serum albumin was less than $4.1 \mathrm{~g} . / 100 \mathrm{ml}$. in 13 patients. One of these (case 35 ) had an increased excretion of P.V.P. $\mathbf{I}^{131}$ though his faecal fat excretion was normal. At no time during the past six years has his serum albumin exceeded $3.9 \mathrm{~g} . / 100 \mathrm{ml}$. Xylose excretion tests were normal in five of the eight patients checked whilst folic acid excretion tests were normal in eight of the 11 patients rechecked. Similarly the folic acid absorption tests were significantly better in eight of the 10 patients checked (Fig. 14) than in tests on those not on a gluten-free diet.

Two or more biopsies have been performed on 14 patients with intervals of at least 12 months between them. Of these six have shown no significant change and, though the reminder have shown considerable improvement in the formation of the villi, abnormalities in the surface epithelium are still to be seen (Fig. 15). Despite considerable clinical improvement some patients still had marked steatorrhoea. None of these 20 patients have become completely normal as assessed by the various tests indicated in this article despite their good general condition.

MILK-FREE DIET Two patients have shown marked improvement since omitting milk from their glutenfree diet. Case 41 , who had been on a gluten-free diet for five years, gained $28 \mathrm{lb}$. in weight in nine months. Previously he had four or five loose stools daily containing 20-30 g. fat: now he passes one formed

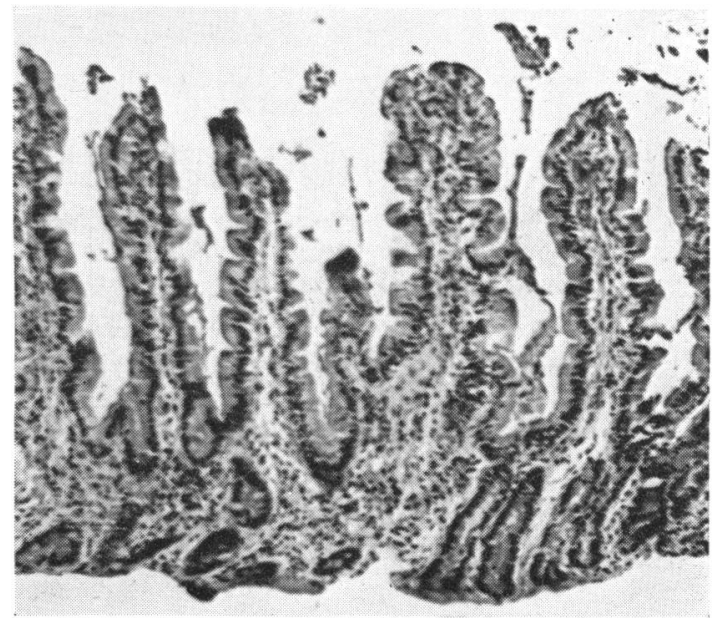

FIG. 15

FIG. 14

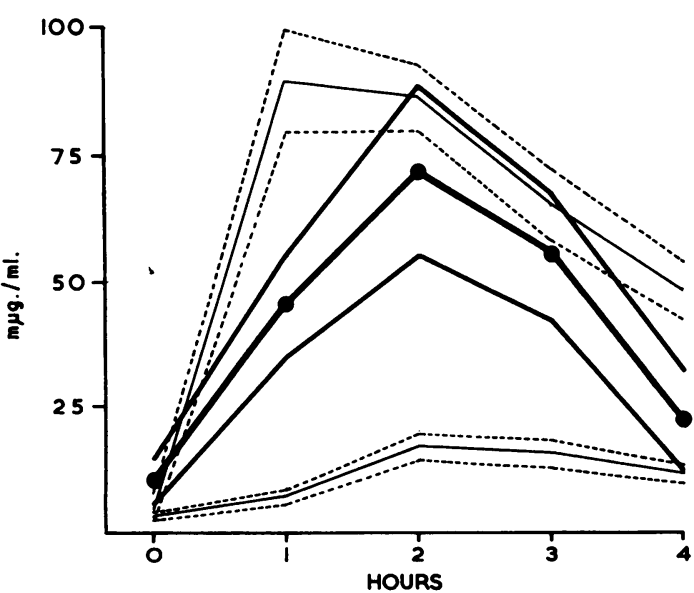

FIG. 14. Comparison of the folic acid absorption test in 10 patients with adult coeliac disease on a gluten-free diet (heavy lines) with 10 normal subjects and 15 patients with adult coeliac disease (light lines). The limits represent one standard error of the mean.

FIG. 15. Jejunal biopsy in case 39 who had been on a gluten-free diet for four years, showing considerable improvement. 


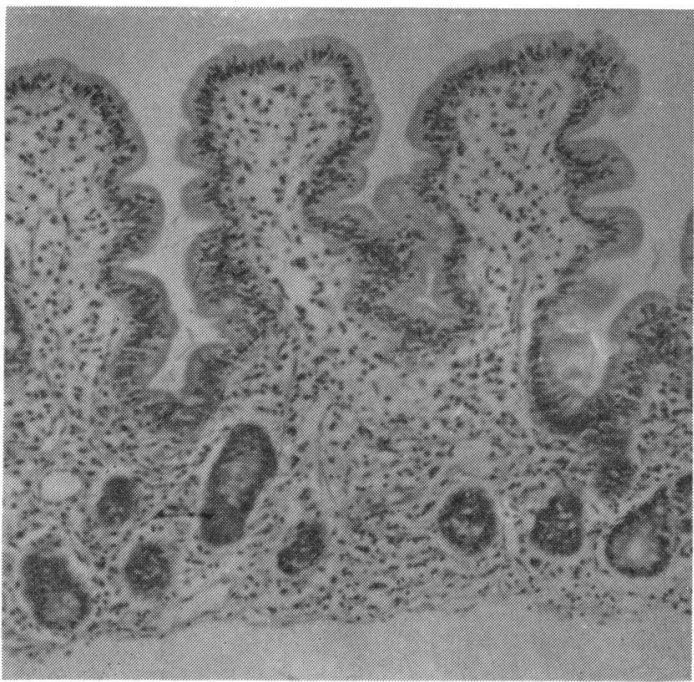

FIG. 16. Jejunal biopsy of case 41, 11 months after the exclusion of milk from his gluten-free diet.

stool daily with $2.5 \mathrm{~g}$. fat. His jejunal biopsy, previously unchanged by a gluten-free diet, is now nearly normal (Fig. 16). Reintroduction of milk led to deterioration of the jejunal mucosa and increase in fat excretion to $14 \mathrm{~g}$. daily. Case 40 , a woman aged 41 , though appearing clinically well had continued to have three or four loose stools on a gluten-free diet. Withdrawal of milk has led to the passage of formed stools once or twice a day for the past six months.

\section{DISCUSSION}

In the majority of patients, adult coeliac disease is a relatively mild disorder. Long periods of good health may be enjoyed without therapy. Severe clinical manifestations in childhood in no way militate against the attainment of excellent health and normal biochemical findings in adult life, and this outcome is not dependant on the adoption of a gluten-free diet. Thus the natural course of this disease makes any assessment of the effects of a gluten-free diet difficult if studies are performed on patients in early adult life, a period when they are usually well.

When first seen the majority of patients have a mild insignificant anaemia, but despite the evidence of poor absorption and malutilization of folic acid, the low serum and whole blood concentrations of 'folic acid', the frequent finding of Figlu in the urine, and histological abnormalities in the area of the intestine where folic acid is absorbed, severe megaloblastic anaemia is uncommon. The occurrence of Figlu in adult coeliac disease has some similarity to the findings in cirrhosis of the liver, in which Carter,
Helle, Schaffner, and Korn (1961) reported the persistence of Figlu in many cases despite the administration of folic acid. Megaloblastic erythropoiesis is probably frequent if looked for and a mild macrocytic anaemia responding to folic acid is common. Patients may maintain this mild degree of anaemia for years without treatment and without developing a severe megaloblastic anaemia. In those patients who do, superimposed infection may well be a precipitating factor and was present in two of the patients with a severe megaloblastic anaemia. Mild degrees of iron deficiency are common, as might be expected from the site of the intestinal lesions, but anaemia due to deficiency of vitamin B12 is infrequent and in this study was only encountered in six patients. In each of these, intrinsic factor was present and impairment of ileal function was presumed. However, the occurrence of severe gastric atrophy in adult coeliac disease makes it probable that intrinsic factor will be absent occasionally.

An important complication of adult coeliac disease which has received very little attention is neuropathy. In this group there were four patients with this complication, which was rapidly fatal in one. The main features are those of ataxia affecting the lower limbs principally, occasionally more marked on one side than another, with flexor plantar responses and absent or reduced leg reflexes. The cause of the abnormality is not clear. Vitamin B12 was absorbed normally by two patients and was present in normal amounts in the serum of the third. The fourth patient had had low levels of vitamin B12 for which he was receiving therapy before the appearance of the neurological complications Neuropathy is not prevented by a gluten-free diet, for it developed in two patients while taking a gluten-free diet and in another patient not included in this series after five years on a gluten-free diet. (These patients are being reported elsewhere more fully with pathological details, together with eight other similar patients.)

As a result of this survey, we have been impressed by the frequency of disturbances of calcium metabolism and mild osteomalacia. The raised serum levels of alkaline phosphatase and the radiological changes in the skeleton were usually associated with 'rheumatic' pains which were alleviated by the administration of calciferol. It is also our impression that the adoption of a gluten-free diet did not prevent the appearance of osteomalacia. This impression has been strengthened by case 58 , a woman who has maintained a rigidly strict gluten-free diet for eight years and who now has clinical, biochemical, and radiological evidence of osteomalacia.

The jejunal mucosa remained flat in two patients in good health and without steatorrhoea who had 
not received a gluten-free diet. Whether the jejunal mucosa can return to normal or near normal without a gluten-free diet must for the present await further study. As has been noted by many workers, a gluten-free diet may bring about a rapid improvement in the clinical condition of many patients and also cause the jejunal mucosa to approach normality, though whether this is ever histologically normal must also remain for future observation. ln our study, however, there was no striking correlation between laboratory findings and the appearances of the jejunal mucosa. One patient with normal folic, xylose, and fat excretion still had a flat biopsy whilst another with marked steatorrhoea, poor folic acid excretion, and abnormal xylose excretion had a jejunal biopsy which was almost normal.

The use of the tanned red cell technique to detect antibodies to fraction III has not yet yielded conclusive results. There was a much greater incidence of reactions to milk products-casein, $\alpha$-lactalbumin, and particularly to $\beta$-lactoglobulin-in these patients. The elimination of milk products from the diets of two led to a significant improvement in their loose stools; the titres were not elevated in one and were $1 / 2,000$ against both a lactalbumin and $\beta$-lactoglobulin in the other. The serum reactions to these antigens will need to be correlated with the clinical state of the patients for some years before their true significance can be determined.

Apart from the biopsy findings, there was surprisingly little difference between patients on a glutenfree diet and those not. The general clinical condition and average increase in weight were comparable in both therapeutic groups. Both the folic acid and the xylose excretion tests showed considerable improvement on a gluten-free diet in many but not all the patients, but there was no significant difference in the level of folic acid activity (assayed with Strep. faecalis) of whole blood which remained low. Also folic acid deficiency was present in three of four patients on a gluten-free diet if the presence of an excess of Figlu in the urine be accepted as evidence. Similarly fat excretion was normal in a higher percentage of those on a gluten-free diet, though it should be noted that faecal excretion was normal in two patients not so treated. However, despite these improvements a high percentage of both groups had raised alkaline phosphatase and low albumin levels in their sera.

There is no doubt that the majority of patients with adult coeliac disease are sensitive to the breakdown products of gluten. Some retain this sensitivity in an acute form so that the introduction of gluten into the diet rapidly produces a severe diarrhoea. On the other hand, it seems clear that some coeliac children eventually tolerate gluten in their diet without any apparent short-term ill effects. It is also evident that many patients with adult coeliac disease tolerate fairly large quantities of gluten in their diet. It is probable that most patients are well in their third and fourth decades even though they still have a flat biopsy. Adult coeliac disease seems to follow a general pattern-poor health in childhood, good health in early adult life, and a tendency to relapse for many reasons between 35 and 55-the period when most of our adult patients came under our care.

Our findings lead us to suppose that a gluten-free diet is of value in helping our patients to return to their usual but slightly defective level of health. Gluten is not the prime cause of the disorder but its omission from the diet is one of the more important factors in treatment. In other words, there is still an underlying constitutional defect, probably enzymatic, which is least manifest when the adult is most active biologically - in early adult life.

The response of the intestine of these patients to 'injury' is not normal. The relatively transitory diarrhoea which may occur in normal subjects following upper respiratory, viral, or gastrointestinal infections readily becomes a prolonged and debilitating diarrhoea in the patients with adult coeliac disease. It is difficult to determine the original cause of the diarrhoea in the majority of these exacerbations but in some patients, only the elimination of a pathogenic organism from the stools will allow the diarrhoea to settle. It is likely that at these times the mucosa becomes particularly sensitive to dietary antigens such as gluten, occasionally to milk proteins, and possibly to certain other dietary products.

We wish to thank our colleagues in the United Birmingham Hospitals for their ready cooperation in allowing us to study many of these patients, and Dr. D. B. Brewer for his help with the biopsies. We should also tender our appreciation to Sister Tillotson and Dr. C. Tasman Jones for their assistance in many of the investigations. We are indebted to the Medical Research Endowment Fund of the United Birmingham Hospitals for personal grants to one of us (D. J. F.) and for the provision of much equipment and technical assistance.

\section{REFERENCES}

\footnotetext{
Carter, F. C., Helle, P., Schaffner, G., and Korn, R. J. (1961). Formiminoglutamic acid (FIGLU) excretion in hepatic cirrhosis. Arch. intern. Med., 108, 41-46.

Cooke, W. T. (1958). Adult coeliac disease and other disorders associated with steatorrhoea. Brit. med. J., 2, 261-265.

- Fowler, D. I., Cox, E. V., Gaddie, R., and Meynell, M. J. (1958). The clinical significance of seromucoids in regional ileitis and ulcerative colitis. Gastroenterology, 34, 910.

- Peeney, A. L. P., and Hawkins, C. F. (1953). Symptoms, signs, and diagnostic features of idiopathic steatorrhoea. Quart. J. Med., 22, 59-77.
} 
_, Thomas, G., Mangall, D., and Cross, H. (1953). Observations on the faecal excretion of total solids, nitrogen, sodium, potassium, water, and fat in the steatorrhoea syndrome. Clin. Sci., 12, 223-234.

Cox, E. V., Meynell, M. J., Cooke, W. T., and Gaddie, R. (1958). The folic acid excretion test in the steatorrhoea syndrome. Gastroenterology, 35, 390-397.

- Cooke, W. T., Meynell, M. J., and Gaddie, R. (1962). Effect of iron and folic acid administration in patients with regaloblastic anaemia and low serum B12 levels. Vitamin B12 and Instrinsic Factor. 2nd European Symposium, pp. 756-760. Enke, Stuttgart.

Fone, D. J., Cooke, W. T., Meynell, M. J., Brewer, D. B., Harris, E. L., and Cox, E. V. (1960). Jejunal biopsy in adult coeliac disease and allied disorders. Lancet, 1, 933-938.

—, Cooke, W. T., Meynell, M. J., and Harris, E. L. (1961). Co ${ }^{58} \mathbf{B}_{12}$ absorption (hepatic surface count) after gastrectomy, ilial resection, and in coeliac disorders. Gut, 2, 218-224.

Fowler, D. I. (1961). Unpublished observations.

$\longrightarrow$, and Cooke, W. T. (1960). Diagnostic significance of D-xylose excretion test. Gut, 1, 67-70.

-, Cox, E. V., Cooke, W. T., and Meynell, M. J. (1960). Aminoaciduria and megaloblastic anaemia. J. clin. Path., 13, 230.

- Fone, D. J., and Cooke, W. T. (1961). The calcium fractions of plasma in hypercalcaemic conditions and in adult coeliac disease. Lancet, 2, 284-287.

Frazer, A. C. (1960). Pathogenetic concepts of the malabsorption syndrome. Gastroenterology, 38, 389-398.

_ Fletcher, R. F., Ross, C. A. C., Shaw, B., Sammons, H. G,. and Schneider, R. (1959). Gluten-induced enteropathy. The effect of partially digested gluten. Lancet, 2, 252-255.

Girdwood, R. H., Delamore, I. W., and Williams, A. Wynn (1961). Jejunal biopsy in malabsorptive disorders of the adult. Brit. med. J., 1, 319-323.

Hawkins, C. F., Peeney, A. L. P., and Cooke, W. T. (1950). Refractory hypochromic anaemia and steatorrhoea. Lancet, 2 , 387-391.
Joske, R. A., and Benson, J. A. Jr. (1958). ABO blood groups and nontropical sprue. Gastroenterology, 34, 408-409.

King, E. J., Haslewood, G. A. D., Delory, G. E., and Beall, D. (1942). Micro-chemical methods of blood analysis. Lancet, 1, 207-209.

Meynell, M. J. (1962). Unpublished observations.

$\longrightarrow$, Cooke, W. T., Cox, E. V., and Gaddie, R. (1957). Serumcyanocobalamin level in chronic intestinal disorders. Lancet, 1 , 901-904.

Mollin, D. L., Waters, A. H., and Harriss, E. (1962). Clinical aspects of the metabolic interrelationships between folic acid and vitamin B12. Vitamin B12 and Intrinsic Factor. 2nd European Symposium, pp. 737-755. Enke, Stuttgart.

Padykula, H. A., Strauss, E. W., Ladman, A. J., and Gardner, F. H. (1961). A morphologic and histochemical analysis of the human jejunal epithelium in nontropical sprue. Gastroenterology, 40, 735-765.

Parsons, L. G., and Barling, S. G. (1954). Diseases of Infancy and Childhood, fig. 49, p. 386. Oxford University Press, London.

Schein, J. (1947). Syndrome of nontropical sprue with hitherto undescribed lesions of the intestine. Gastroenterology, 8, 438-460.

Sencer, W. (1957). Neurologic manifestations in the malabsorption syndrome. J. Mt Sinai Hosp., 24, 331-345.

Shiner, M., and Doniach, I. (1959). Histopathologic Studies in Steatorrhoea. Proceedings of the World Congress of Gastroenterology, 1958, vol. 1, pp. 586-607. Williams and Wilkins, Baltimore.

Tabor, H., and Wyngarten, L. (1958). A method for the determination of formiminoglutamic acid in urine. J. clin. Invest., 37, 824-828.

Waters, A. H., and Mollin, D. L. (1961). Studies on the folic acid activity of human serum. J. clin. Path., 14, 335-344.

Weichselbaum, T. E. (1946). An accurate and rapid method for the determination of proteins in small amounts of blood, serum and plasma. Amer. J. Clin. Path. (tech. sect.), 10, 40-49.

Witts, L. J. (1952). In Modern Trends in Gastroenterology, edited by F. Avery Jones, p. 4. Butterworth, London. 